\title{
Vanilloid-Mediated Heterosynaptic Facilitation of Inhibitory Synaptic Input to Neurons of the Rat Dorsal Motor Nucleus of the Vagus
}

\author{
Andrei V. Derbenev, Michael J. Monroe, Nicholas R. Glatzer, and Bret N. Smith \\ Department of Cell and Molecular Biology, Division of Neurobiology, Tulane University, New Orleans, Louisiana 70118
}

\begin{abstract}
Vanilloid type-1 receptors (VR1) are abundant in the dorsal vagal complex, where their function is mostly unknown. We examined the role of VR1 in regulating synaptic inputs to neurons of the dorsal motor nucleus of the vagus (DMV). Using patch-clamp recordings from DMV neurons in brainstem slices, capsaicin was found to increase action potential-independent inhibitory input onto DMV neurons. This rapid effect was mimicked by application of the endogenous cannabinoid, anandamide and blocked by VR1 antagonists. The VR1-mediated facilitation of synaptic inhibition was reduced by ionotropic and metabotropic glutamate receptor antagonists, suggesting an indirect, heterosynaptic enhancement of GABA release caused by a VR1-mediated increase in glutamate release from presynaptic terminals of excitatory neurons. Application of L-glutamate also increased GABA release. The paired-pulse ratio was increased for IPSCs evoked after electrical stimulation of the nucleus tractus solitarius, but the effect was slower than for the enhancement of spontaneous and miniature IPSCs. Capsaicin also increased the frequency of glutamatergic postsynaptic currents in a VR1-mediated manner. Results of these studies suggest that VR1-containing glutamatergic terminals contact DMV neurons. Activation of VR1 potently enhances glutamate release onto GABAergic terminals, facilitating GABA release. Endogenous cannabinoids can thereby rapidly enhance inhibitory input to DMV neurons via VR1-mediated presynaptic mechanisms.
\end{abstract}

Key words: anandamide; cannabinoid; capsaicin; gastric; nucleus tractus solitarius; presynaptic

\section{Introduction}

The dorsal vagal complex (DVC) in the dorsomedial medulla consists of area postrema, the nucleus of the solitary tract (NTS), and the dorsal motor nucleus of the vagus (DMV). Neurons in the NTS receive visceral mechanosensory and chemosensory input via primary vagal, glossopharyngeal, and facial nerve afferents, whose central processes form the solitary tract in the hindbrain. Neurons of the DMV constitute the preganglionic motor neurons that project throughout most of the gastrointestinal tract, among other viscera (Laughton and Powley, 1987). Together, the viscerosensory branch, integrative centers within the DVC, and motor fibers from the DMV complete vagal reflex pathways (Raybould et al., 1991; Rogers et al., 1996).

The vanilloid type-1 receptor (VR1) is a ligand-gated nonselective cation channel with high $\mathrm{Ca}^{2+}$ permeability that is structurally related to a member of the transient receptor potential (TRP) channel family. These receptors are sensitive to capsaicin and also to temperature and $\mathrm{pH}$ changes (Tominaga et al., 1998; Szallasi and Blumberg, 1999), and activation is often associated

Received June 27, 2005; revised Aug. 10, 2006; accepted Aug. 11, 2006. This work was supported by National Institutes of Health Grant DK56132.

Correspondence should be addressed to Dr. Bret N. Smith, University of Kentucky, College of Medicine, Department of Physiology, MS-509 Chandler Medical Center, Lexington, KY 40536-0298. E-mail: Bret.Smith@UKY.edu. D0I:10.1523/JNEUROSCI.1591-06.2006

Copyright $\odot 2006$ Society for Neuroscience $\quad$ 0270-6474/06/269666-07\$15.00/0 with nociception in peripheral nerves. Recently, endocannabinoids, including anandamide (AEA), have also been shown to activate VR1 in the CNS (Szallasi and Di Marzo, 2000; Szolcsányi, 2000; Jennings et al., 2003; Marinelli et al., 2003). Centrally, VR1 are expressed in the spinal cord dorsal horn, as well as several discrete brain regions (Acs and Blumberg, 1994; Szallasi et al., 1995; Acs et al., 1996; Caterina et al., 1997; Mezey et al., 2000; Li et al., 2004), including the DVC (Patterson et al., 2003).

Little is known about the physiological role of VR1 receptors in the hindbrain. Electrophysiological studies in the NTS indicate that capsaicin activates a subset of solitary tract axons to transiently enhance release of glutamate onto second-order viscerosensory neurons (Doyle et al., 2002; Jin et al., 2004a). Synaptic responses to vagal stimulation in cardiac-related DMV neurons are suppressed after $>30$ min of continuous capsaicin application, but this is probably because of time-dependent inactivation of vagal afferents (Evans et al., 2003). Recent studies have addressed the roles of central VR1 activation on respiratory rate (Geraghty and Mazzone, 2002), gastric acid secretion (Minowa et al., 2001), and emesis (Shiroshita et al., 1997), with emphasis on sensory modulation. However, the rapid effects of capsaicin on neurons of the DMV have not been studied in detail.

We investigated the role of VR1 in the control of excitatory and inhibitory synaptic inputs to DMV neurons using in vitro electrophysiological recordings to test the hypothesis that VR1 receptor activation potentiates synaptic input to DMV neurons. 


\section{Materials and Methods}

All procedures were performed on male Sprague Dawley rats (Harlan, Indianapolis, IN) and were approved by the Tulane University Animal Care and Use Committee.

Brainstem slice preparation. Transverse brainstem slices were prepared from male Sprague Dawley rats (Harlan), 4-8 weeks of age, as described previously (Derbenev et al., 2004a). Rats were deeply anesthetized by halothane inhalation and killed by rapid decapitation while anesthetized. Brains were rapidly removed and immersed in ice-cold $\left(0-4^{\circ} \mathrm{C}\right)$ oxygenated $\left(95 \% \mathrm{O}_{2}-5 \% \mathrm{CO}_{2}\right.$ ) artificial CSF (ACSF) containing the following (in $\mathrm{mM}$ ): $124 \mathrm{NaCl}, 3 \mathrm{KCl}, 26 \mathrm{NaHCO}_{3}, 1.4 \mathrm{NaH}_{2} \mathrm{PO}_{4}, 11$ glucose, 1.3 $\mathrm{CaCl}_{2}$, and $1.3 \mathrm{MgCl}_{2}, \mathrm{pH}$ 7.3-7.4, with an osmolality of $290-310$ $\mathrm{mOsm} / \mathrm{kg}$. Transverse brainstem slices $(350-400 \mu \mathrm{m})$ containing the DVC were made using a vibrating microtome (Vibratome Series 1000; Technical Products, St. Louis, MO). The slice experiments were performed at $32^{\circ} \mathrm{C}$. Slices were transferred to a recording chamber mounted on a fixed stage under an upright microscope (BX51WI; Olympus, Melville, NY).

Whole-cell recording. Neurons in the DMV were visually targeted for recording under a $40 \times$ water-immersion objective using infrared differential interference contrast optics (Olympus). For whole-cell patchclamp recordings, electrodes $(2-4 \mathrm{M} \Omega$ ) were filled with a solution containing the following (in $\mathrm{mm}$ ): $130 \mathrm{Cs}^{+}$-gluconate, $1 \mathrm{NaCl}, 5 \mathrm{EGTA}, 10$ HEPES, $1 \mathrm{MgCl}_{2}, 1 \mathrm{CaCl}_{2}, 3 \mathrm{CsOH}, 2-4 \mathrm{Mg}$-ATP, and $0.2 \%$ biocytin, $\mathrm{pH}$ 7.3-7.4, adjusted with $5 \mathrm{~m} \mathrm{CsOH}$. IPSCs were examined at a holding potential of $-10 \mathrm{mV}$; EPSCs were recorded at $-60 \mathrm{mV}$. Electrophysiological signals were low-pass filtered at $2-5 \mathrm{kHz}$, digitized at $88 \mathrm{~Hz}$, recorded using an Axopatch 200B or 700A amplifier (Molecular Devices, Union City, CA), and analyzed with pClamp 8 software (Molecular Devices). Spontaneous and evoked IPSCs and EPSCs were analyzed offline using pClamp 8 or MiniAnalysis (Synaptosoft, Decatur, GA). Synaptic currents were evoked by electrical stimulation using a concentric bipolar platinum-iridium electrode (200 $\mu \mathrm{m}$ outer diameter; FHC, Bowdoinham, ME) placed on the medial portion of the NTS. Evoked EPSCs and IPSCs had short, constant latency (variation in response latency $<0.5$ $\mathrm{ms}$ ), and $<20 \%$ failure rate. The NTS was stimulated by paired current pulses $(300 \mu \mathrm{s})$ at pairing frequencies of $10-20 \mathrm{~Hz}$, with $10 \mathrm{~s}$ interstimulus interval.

Drug application. Most experiments were performed with tetrodotoxin (TTX; $1-2 \mu \mathrm{M}$ ) in the bath solution. Capsaicin, capsazepine, and 5 '-iodoresiniferatoxin (Tocris Bioscience, Ellisville, $\mathrm{MO}$ ) were dissolved in ethanol and diluted in ACSF (final concentration of ethanol $<0.01 \%$ by volume). AEA was purchased predissolved in Tocrisolve (Tocris Bioscience). Vehicle alone (i.e., ethanol or Tocrisolve) had no effect on membrane or synaptic properties $(n=5$ each). Capsaicin, AEA, or L-glutamate were bath applied for 5-10 min at a final concentration of 1 nM-100 $\mu \mathrm{M}$. In other experiments, capsaicin (10 $\mu \mathrm{m}$; $\mathrm{pH} 7.3-7.4)$ or AEA (50 $\mu \mathrm{M} ; \mathrm{pH} 7.3-7.4)$ were pressure-applied (5 psi; $100 \mathrm{~ms}$ ) near the recorded neuron via a glass pipette $(\sim 2 \mu \mathrm{m}$ tip diameter $)$ attached to a Picospritzer (Parker-Hannefin, Fairfield, NJ). Antagonists to VR1, capsazepine $(20 \mu \mathrm{M})$ or $5^{\prime}$-iodoresiniferatoxin $(1 \mu \mathrm{M})$, or cannabinoid type 1 receptors (CB1R) (AM251, $10 \mu \mathrm{M}$; Tocris Bioscience) were applied with the bath for 10 min before agonist application to isolate effects of endocannabinoid agonists. Ionotropic glutamate receptor antagonists DL-5aminophosphonovaleric acid (AP-5, $50 \mu \mathrm{M}$; Sigma, St. Louis, MO) and 6-cyano-7-nitroquinoxaline-2,3-dione (CNQX, $10 \mu \mathrm{M}$; Sigma), or a mixture of type I/II metabotropic [ $\alpha$-methyl-4-carboxyphenylglycine (MCPG), 1 mu and type III [ $\alpha$-methylserine-O-phosphate (MSOP), 250 $\mu \mathrm{M}]$ metabotropic glutamate receptor antagonists (both from Tocris Bioscience), were bath applied for $10 \mathrm{~min}$ in some instances before capsaicin application to determine the role of glutamate receptors in effects of VR1 actions on synaptic input. At these concentrations, the antagonists were shown to block all ionotropic and metabotropic glutamate receptors (Derbenev et al., 2004a; Drew and Vaughan, 2004).

Data analysis. The effects of VR1 agonists on spontaneous postsynaptic current (PSC) frequency and amplitude were analyzed within individual neurons using the Kolmogorov-Smirnov test. The effects of agonists on PSC frequency across the neuron population were analyzed

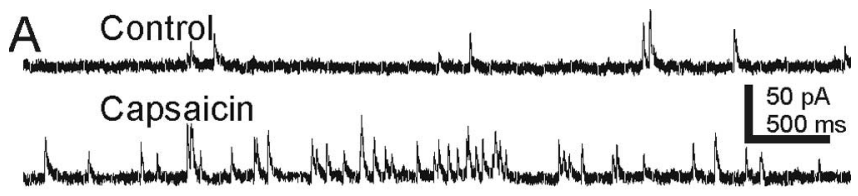

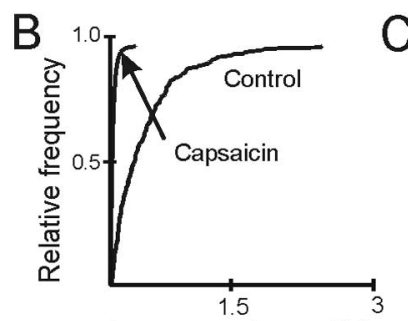

Inter-event interval(s)
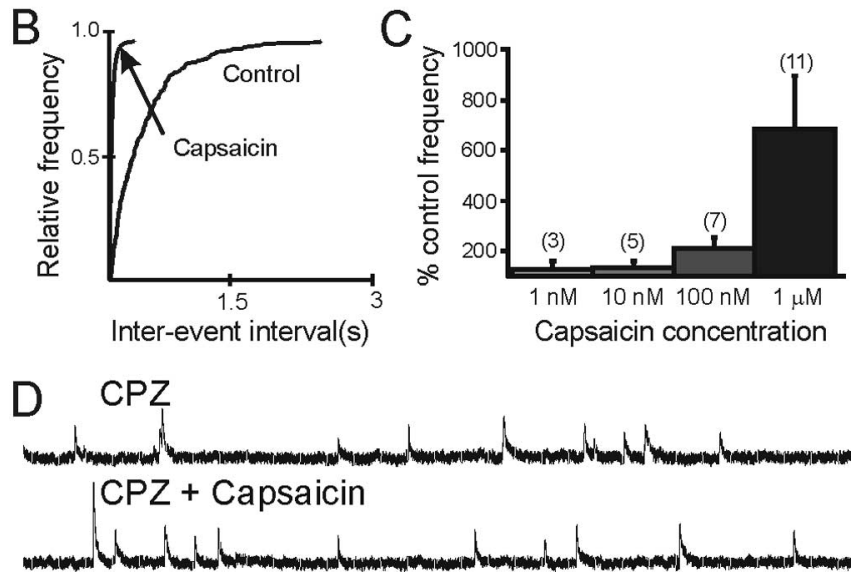

Figure 1. The VR1 agonist capsaicin increased mIPSC frequency in DMV neurons. $\boldsymbol{A}$, Continuous recording of mIPSCs observed at holding potential of $-10 \mathrm{mV}$ in the presence of TTX (1 $\mu \mathrm{m}$; top) and after application of $1 \mu \mathrm{m}$ capsaicin (bottom). The recording pipette contained 140 $\mathrm{mm} C s^{+} . \boldsymbol{B}$, Cumulative plots of the interevent interval distribution for mIPSCs before and after perfusion of capsaicin ( $p<0.05$, Kolmogorov-Smirnov test). $\boldsymbol{C}$, Concentration-related effect of capsaicin. Numbers of replicates are in parentheses above each bar. $D$, Recordings of mIPSCS at a holding potential of $-10 \mathrm{mV}$ in the presence of the VR1 antagonist capsazepine (CPZ; 20 $\mu \mathrm{M}$ ) before (top) and after application of capsaicin (1 $\mu \mathrm{M})$ (bottom). Calibration is the same for $\boldsymbol{A}$ and $\boldsymbol{D}$. Error bars indicate $\mathrm{SE}$.

using a paired two-tailed Student's $t$ test. The effects of the glutamate antagonists on capsaicin were compared using one-way ANOVA followed by a Dunn's test. For electrical stimulation analysis, we compared the stimulus amplitudes of the successful responses (i.e., a PSC was evoked by the stimulus) in the presence of capsaicin versus the control amplitudes with an unpaired Student's $t$ test. Paired-pulse ratios were calculated as the average amplitudes of the second PSC divided by the first and compared across neurons using the paired Student's $t$ test. For all analyses, $p<0.05$ was considered significant. Values are reported as the mean \pm SEM.

\section{Results}

\section{Capsaicin effects on mIPSC frequency in DMV neurons}

To assess the effects of VR1 activation on GABA release in the DMV, the effects of capsaicin on miniature IPSCs (mIPSCs) were examined in DMV neurons in the presence of TTX $(1 \mu \mathrm{M})$. Neurons were voltage-clamped at $-10 \mathrm{mV}$ using $\mathrm{Cs}^{+}$in the recording pipette to block voltage-dependent $\mathrm{K}^{+}$channels and consequently improve voltage clamp and facilitate mIPSC analysis (Davis et al., 2003; Derbenev et al., 2004a). Bath application of capsaicin $(1 \mu \mathrm{M})$ significantly increased the frequency of mIPSCs in each of 11 DMV cells (Fig. 1). The effect of capsaicin was observed within 2 min of the drug reaching the slice and was maximal by $5 \mathrm{~min}$. Under control conditions, the average mIPSC frequency was $1.8 \pm 0.3 \mathrm{~Hz}$ and ranged from 0.8 to $3.1 \mathrm{~Hz}$. After application of the highest concentration of capsaicin tested (1 $\mu \mathrm{M} ; 5-7 \mathrm{~min}$ ), the mean frequency of mIPSCs was increased to $10.6 \pm 3 \mathrm{~Hz}$ (range, $2.6-29.2 \mathrm{~Hz} ; p<0.05 ; n=11$ ) (Fig. 1). Application of different log concentrations of capsaicin (1 nM-1 $\mu \mathrm{M})$ resulted in a concentration-related increase in the frequency of mIPSCs (Fig. 1C). There was no significant change in mIPSC amplitude after application of $1 \mu \mathrm{M}$ of capsaicin $(p>0.05)$. The average amplitude before application of capsaicin was $27 \pm 2 \mathrm{pA}$ 
( $n=11$; range, $17-36 \mathrm{pA})$ and after bath application of $1 \mu \mathrm{M}$ of capsaicin was $31 \pm 3 \mathrm{pA}$ (range, $19-53 \mathrm{pA}$ ).

To verify that the effect of capsaicin on IIPSC frequency was mediated by VR1 receptors, capsazepine $(20 \mu \mathrm{M})$ was applied before and during capsaicin application. Capsazepine itself had no effect on the frequency of mIPSCs but completely prevented the effect of capsaicin (Fig. 1D). The frequency of mIPSCs was $2.7 \pm 0.5 \mathrm{~Hz}$ (range, $1.3-4.2 \mathrm{~Hz}$ ) in the presence of capsazepine and $2.1 \pm 0.4 \mathrm{~Hz}$ (range, 1.3-4 Hz) after bath application of capsaicin $(1 \mu \mathrm{M})$ in the presence of capsazepine $(p>0.05 ; n=7)$.

\section{Dependence of VR1-mediated mIPSC facilitation on glutamate receptors}

Under control conditions (i.e., TTX only) in neurons voltageclamped at $-10 \mathrm{mV}$, the frequency of mIPSCs was $1.8 \pm 0.3 \mathrm{~Hz}$ $(n=11)$ (Fig. 2A, top trace). After 3-5 min bath application of capsaicin, mIPSC frequency was increased to $10.6 \pm 2.5 \mathrm{~Hz}(p<$ $0.05 ; n=11)$ and was $11.6 \pm 3.7 \mathrm{~Hz}(p<0.05 ; n=7)($ Fig. $2 A)$ after 8-10 min capsaicin application. In the presence of ionotropic glutamate receptor antagonists CNQX $(10 \mu \mathrm{M})$ and AP-5 $(50 \mu \mathrm{M})$, mIPSC frequency in another set of neurons was $2.9 \pm$ $0.5 \mathrm{~Hz}(n=10)$ (Fig. $2 B)$. The VR1-induced increase in mIPSC frequency in these cells was not significant after $3 \mathrm{~min}(5.5 \pm 1.6$ $\mathrm{Hz} ; n=10 ; p>0.05)$, but became apparent after $10 \mathrm{~min}$ of capsaicin application $(9.1 \pm 3 \mathrm{~Hz} ; p<0.05 ; n=7)$ (Fig. 2 B). In another set of neurons, the selective group III metabotropic glutamate receptor antagonist MSOP $(250 \mu \mathrm{M})$ and nonselective group I/group II metabotropic glutamate receptor antagonist MCPG (1 mM) were applied in addition to the ionotropic antagonists. The frequency of mIPSCs in these cells was $2.1 \pm 0.7 \mathrm{~Hz}$ $(n=8)$. There was no significant effect of capsaicin in these neurons after $3 \mathrm{~min}(3.7 \pm 1.4 \mathrm{~Hz} ; p>0.05 ; n=8)$ or $10 \mathrm{~min}$ $(3.7 \pm 1.5 \mathrm{~Hz} ; p>0.05 ; n=8)$. Ionotropic and metabotropic glutamate receptor antagonists together significantly reduced the effect of capsaicin on MIPSC frequency (Fig. 2D), even at the later time point (i.e., longer capsaicin application), when ionotropic antagonists alone were ineffective in preventing the effect.

In the presence of just the metabotropic glutamate receptor antagonists (MCPG, $1 \mathrm{mM}$, and MSOP, $250 \mu \mathrm{M}$ ), mIPSC frequency in another set of neurons was $4.0 \pm 0.4 \mathrm{~Hz}(n=8)$ (Fig. $2 C)$. The VR1-induced increase in mIPSC frequency in these cells was not significant after $3 \min (6.2 \pm 1.3 \mathrm{~Hz} ; n=8 ; p>0.05)$, or $10 \mathrm{~min}$ of capsaicin application $(5.7 \pm 1.6 \mathrm{~Hz} ; p>0.05 ; n=7)$ (Fig. 2D). The presence of either ionotropic or metabotropic glutamate receptor antagonists significantly reduced the effect of capsaicin on mIPSC frequency (Fig. 2D). Because the VR1mediated enhancement of mIPSCs was prevented by glutamate receptor antagonists, we tested the hypothesis that glutamate itself increased mIPSC frequency. Bath application of L-glutamate $(100 \mu \mathrm{M})$ resulted in a small but significant increase in mIPSC frequency $(1.4 \pm 0.3 \mathrm{~Hz}$; range $0.4-2 \mathrm{~Hz}$ in control vs $2.2 \pm 0.5$ $\mathrm{Hz}$, range $0.6-3 \mathrm{~Hz}$ in glutamate; $p<0.05$, paired $t$ test; $n=7$ ) (Fig. 3).

\section{Capsaicin effects on IPSCs evoked after NTS stimulation}

Paired electrical stimuli applied to the NTS were used to generate pairs of evoked IPSCs in DMV neurons (Fig. 4). The effects of capsaicin were tested on responses to paired stimuli to further assess whether the VR1 agonist acted at a presynaptic site, with a change in the ratio of amplitudes suggesting a presynaptic site of action (Regehr and Stevens, 2001). For IPSCs evoked at a pairing frequency of $10-20 \mathrm{~Hz}$, paired-pulse depression resulted, with the second evoked IPSC having a smaller amplitude than the first
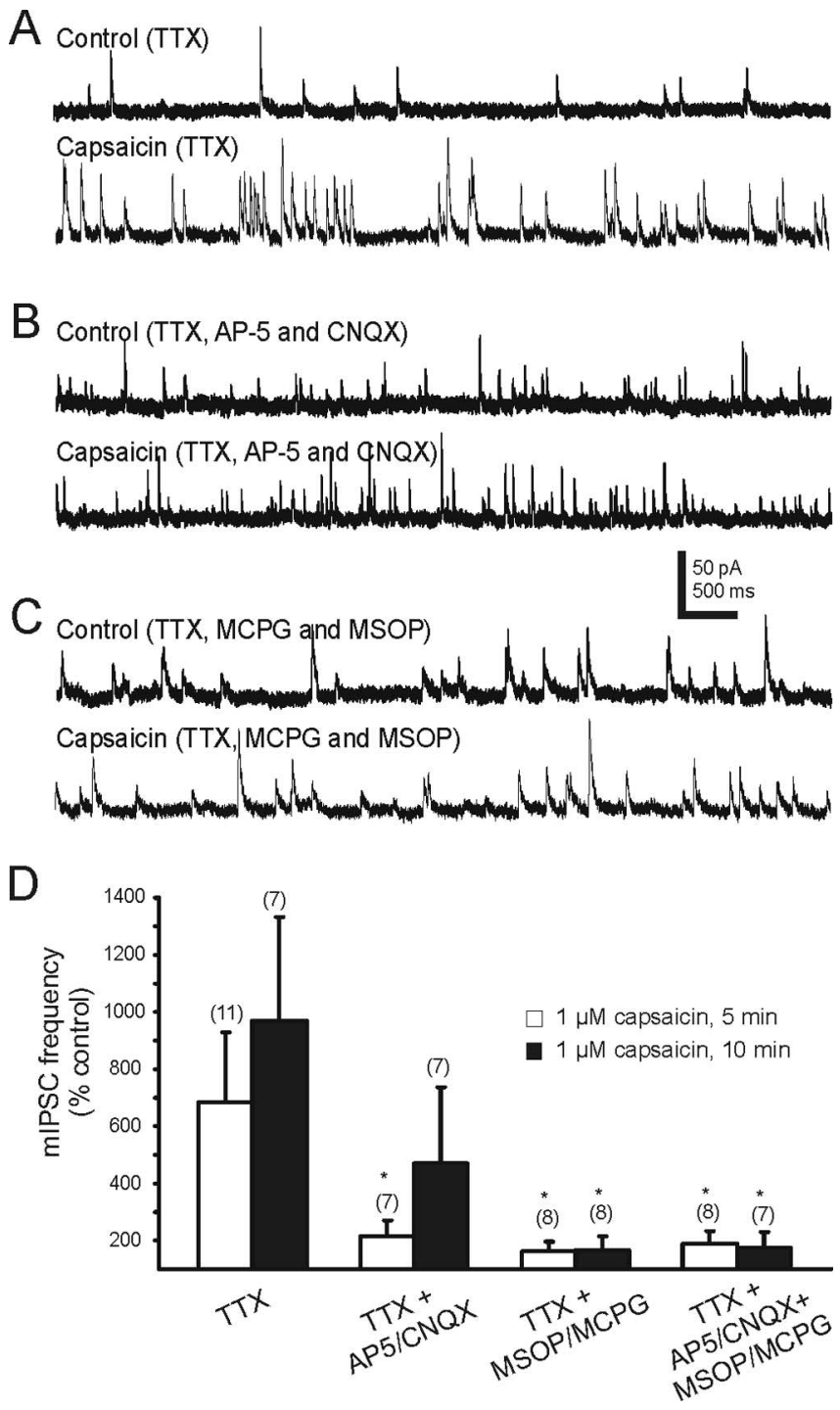

Figure 2. Glutamate receptor antagonists reduced the effect of capsaicin on mIPSCS. $\boldsymbol{A}$, Continuous recordings of mIPSCs at holding potential of $-10 \mathrm{mV}$ in control conditions ( $1 \mu \mathrm{M}$ TTX; top) and 10 min after addition of $1 \mu \mathrm{m}$ capsaicin (bottom). $\boldsymbol{B}$, Continuous recordings of mIPSCs in the presence of $1 \mu \mathrm{M}$ TTX, $10 \mu \mathrm{M}$ CNQX, and $50 \mu \mathrm{M}$ AP- 5 before (top) and 10 min after application of $1 \mu$ m capsaicin (bottom). C, Continuous recordings of mIPSCs at holding potential of $-10 \mathrm{mV}$ in control conditions (top) and after $10 \mathrm{~min}$ bath application of $1 \mu \mathrm{m}$ capsaicin (bottom). ACSF contained $1 \mu \mathrm{m}$ TTX, 1 mm MCPG, and $250 \mu \mathrm{m}$ MSOP. D, Effects of glutamate receptor antagonists on the capsaicin-induced increase in mIPSC frequency, normalized to the frequency before capsaicin application obtained in the presence of drugs indicated, after 3 and 10 min bath application of $1 \mu \mathrm{m}$ capsaicin. Numbers of replicates are in parentheses; the asterisk indicates significance $(p<0.05$ ) versus TTX alone. Error bars indicate SE.

(Fig. 4). The amplitude of the first response was $212 \pm 52 \mathrm{pA}$ and the paired pulse amplitude ratio for these neurons was $0.7 \pm 0.1$ $(n=7)$. Capsaicin had no effect on the amplitude of the first evoked IPSC ( $159 \pm 27 \mathrm{pA} ; p>0.05$, paired $t$ test) or on the paired-pulse ratio $(0.7 \pm 0.1 ; n=7 ; p>0.05)$ within $5 \mathrm{~min}$ of application. However at $10 \mathrm{~min}$, capsaicin reduced the amplitude of the first current $(117 \pm 32 \mathrm{pA} ; p<0.05)$ to a greater degree than the second current, such that the paired-pulse ratio increased to $1.2 \pm 0.2(n=7 ; p<0.05)$ (Fig. 4$)$.

Microapplication of capsaicin and endocannabinoids increased frequency of mIPSCs

In the NTS, capsaicin-induced effects desensitized rapidly (Doyle et al., 2002). To examine rapid effects of VR1 activation, agonists 

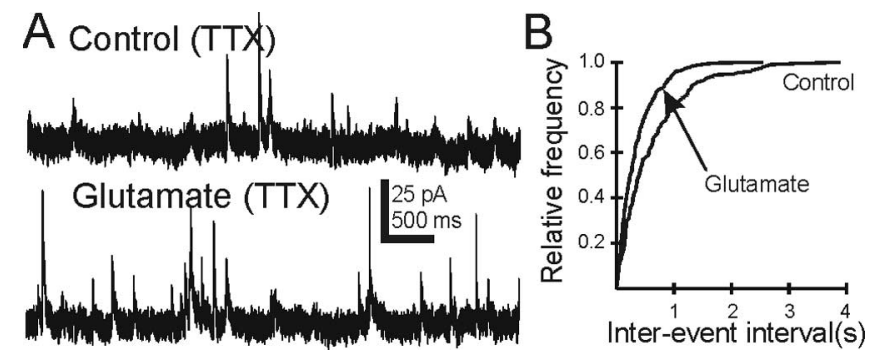

Figure 3. Glutamate increased mIPSC frequency in DMV neurons. $A$, Continuous recording of mIPSCs observed at holding potential of $-10 \mathrm{mV}$ in the presence of TTX (1 $\mu \mathrm{m}$; top) and after application of $100 \mu \mathrm{m}$ L-glutamate (bottom). Recording pipette contained $140 \mathrm{~mm} \mathrm{Cs}{ }^{+}$. $\boldsymbol{B}$, Cumulative plots of the interevent interval distribution for mIPSCs before and after perfusion of capsaicin ( $p<0.05$, Kolmogorov-Smirnov test).
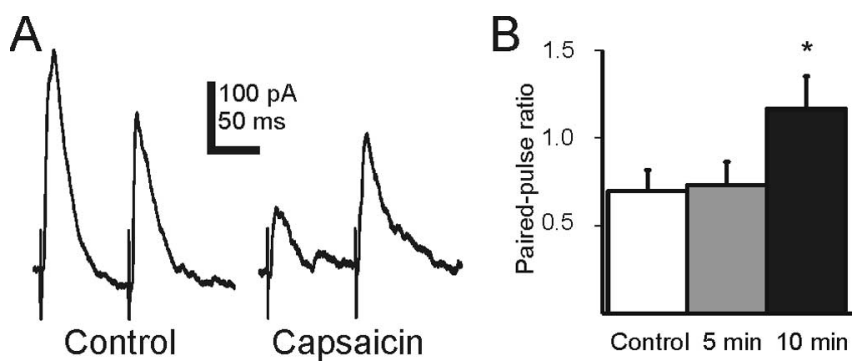

Figure 4. Capsaicin decreased evoked IPSC amplitude via actions at presynaptic receptors. $\boldsymbol{A}$, Average of $15-20$ traces of IPSCs evoked by paired current stimuli $(10 \mathrm{~Hz})$ applied to the NTS. $\boldsymbol{B}$, Paired-pulse ratio for control and after 5 and 10 min capsaicin $(1 \mu \mathrm{m})$ application. The pairedpulse ratio was unchanged after 5 min, but was increased $(p<0.05)$ after 10 min capsaicin application. ${ }^{*} p<0.05$ versus control. Error bars indicate SE.

were applied transiently through a glass pipette positioned near the surface of the slice. Capsaicin or AEA was microapplied very near the recorded DMV neuron, which was voltage clamped at $-10 \mathrm{mV}$ (Fig. 5). Short-duration (100 ms) pressure application of capsaicin $(10 \mu \mathrm{M})$ resulted in a brief increase in mIPSC frequency from a preapplication frequency of $1.9 \pm 0.4 \mathrm{~Hz}$ (range, $1-3.2 \mathrm{~Hz})$ to a capsaicin-induced frequency of $17 \pm 7 \mathrm{~Hz}(p<$ $0.05 ; n=5$; range, $4.1-34 \mathrm{~Hz}$ ) (Fig. $5 A$ ). A facilitation of mIPSCs was also observed after pressure application of the endogenously produced cannabinoid and vanilloid agonist AEA $(50 \mu \mathrm{M})$ from a control frequency of $2.5 \pm 0.5 \mathrm{~Hz}$ (range, $1-6.6 \mathrm{~Hz}$ ) to $16.7 \pm 2.5$ $\mathrm{Hz}$ after AEA application $(p<0.05 ; n=10$; range, $5-35.4 \mathrm{~Hz}$ ) (Fig. $5 B$ ). Preapplication of the VR1 antagonists capsazepine (20 $\mu \mathrm{M} ; n=3)($ Fig. $5 B)$ or $5^{\prime}$-iodoresiniferatoxin (500 nM-1 $\mu \mathrm{M} ; n=$ $10)$, prevented the AEA-induced increase in mIPSC frequency $(0.9 \pm 0.2 \mathrm{~Hz}$ control to $1.3 \pm 0.3 \mathrm{~Hz}$ in AEA; $p>0.05)$.

The effects of endocannabinoids have been shown to involve a significant suppression of mIPSC frequency over a period of 5-15 min (Derbenev et al., 2004a,b). To determine whether AEA activated CB1R along with VR1, we applied AEA $(1 \mu \mathrm{M})$ in the presence of CB1R antagonist AM251 $(10 \mu \mathrm{M})$ and compared the results with those obtained in the absence of the antagonist. In the presence of AM251, application of AEA increased the frequency of mIPSCs from a control frequency of $3.5 \pm 0.8 \mathrm{~Hz}$ (range, $0.8-5.4 \mathrm{~Hz})$ to $48 \pm 8 \mathrm{~Hz}$ after AEA application $(p<0.05 ; n=5$; range, 21-73.4 Hz) (Fig. 5). This increase was significantly greater than for the same application in the absence of the antagonist $(p<0.05)$ (Fig. 5E), suggesting that both VR1 and CB1R were activated by the endocannabinoid. Endocannabinoids altered mIPSC frequency in DMV neurons by acting at both VR1 and CB1R.
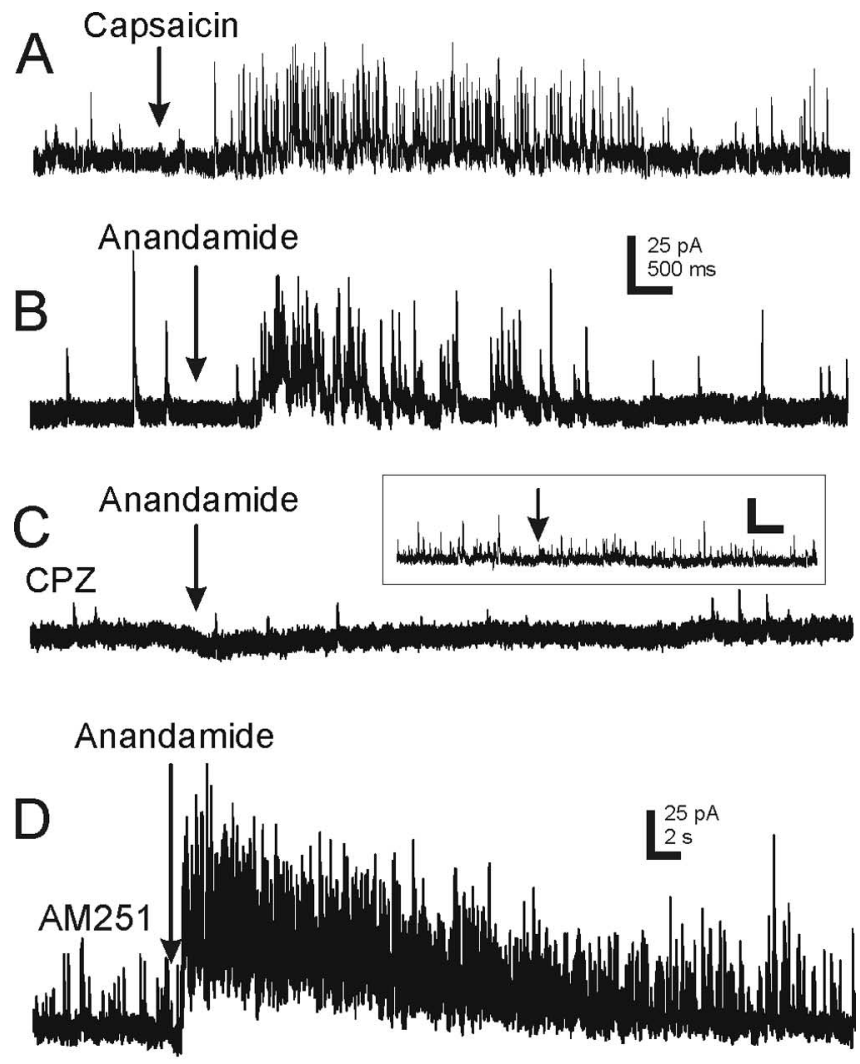

$E$

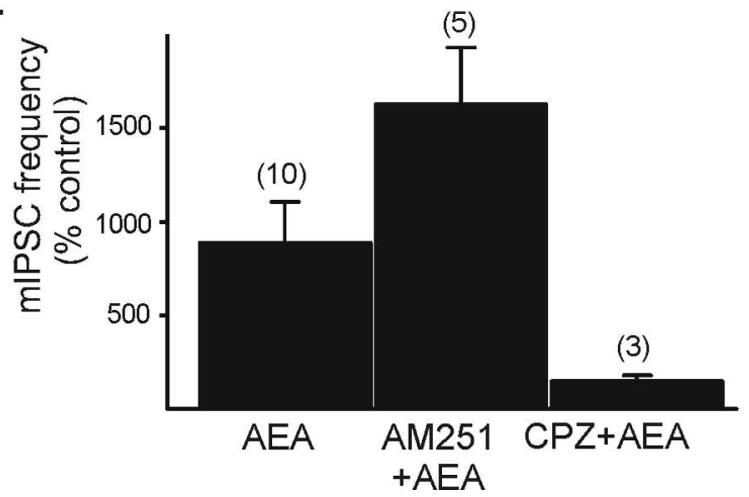

Figure 5. Transient enhancement of mIPSC frequency after microapplication of VR1 agonists. $A$, Rapid ( $100 \mathrm{~ms}$ ) application of $100 \mu \mathrm{m}$ capsaicin near the recorded neuron resulted in a barrage of mIPSCs. $\boldsymbol{B}$, Microapplication (100 ms) of AEA (50 $\mu \mathrm{M}$ ) similarly increased the frequency of mIPSCs. C, Preapplication of capsazepine (CPZ; $20 \mu \mathrm{M})$ blocked the effect of microapplied AEA. Calibration is the same for $\boldsymbol{A}-\boldsymbol{C}$. Inset, Trace in box between $\boldsymbol{B}$ and $\boldsymbol{C}$ shows that identical application of vehicle (i.e., Tocrisolve; arrow) had no effect on mIPSC frequency. $\boldsymbol{D}$, Microapplication of AEA in the presence of AM251 $(10 \mu \mathrm{M})$ resulted in a large barrage of mIPSCS. The holding potential was $-10 \mathrm{mV}$ for all traces; TTX was present in all traces. $E$, Cumulative data showing the AEA-induced increase in mIPSC frequency in TTX, TTX plus AM251, and TTX plus CPZ (20 $\mu \mathrm{M})$. The AEA-induced increase in mIPSC frequency was significantly greater in the presence of the CB1R antagonist AM251 $(p<0.05)$ than without the antagonist. The effect was prevented by capsazepine. Error bars indicate $S E$.

\section{Effect of capsaicin on mEPSCs in DMV neurons}

In each of seven neurons voltage-clamped at $-60 \mathrm{mV}, 1 \mu \mathrm{M}$ capsaicin significantly increased frequency of miniature EPSCs (mEPSCs) from $4.6 \pm 1.2 \mathrm{~Hz}$ before capsaicin application to $16.3 \pm 3.8 \mathrm{~Hz}$ in the presence of capsaicin $(p<0.05)$ (Fig. 6). There was no change in mEPSC amplitude after application of capsaicin compared with control $(p>0.05)$. The average ampli- 
A
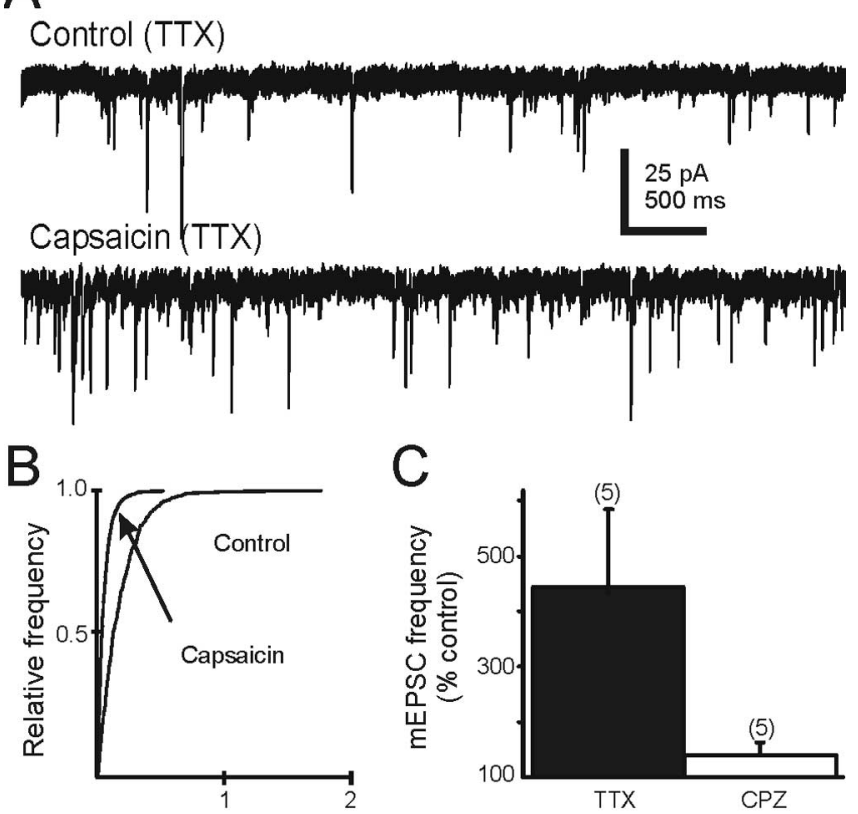

Inter-event interval (s)

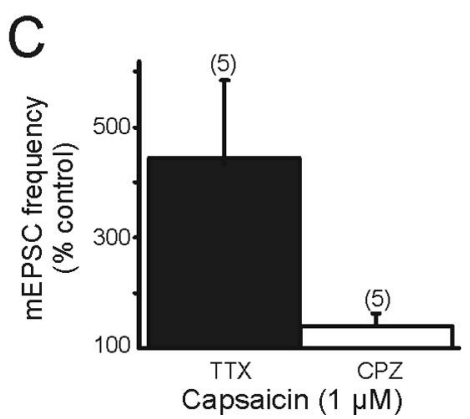

Figure 6. Capsaicin increased mEPSC frequency in DMV neurons. $\boldsymbol{A}$, Continuous recording demonstrating mEPSCs at holding potential $-60 \mathrm{mV}$ in control conditions (top) and after bath application of $1 \mu \mathrm{m}$ capsaicin (bottom). ASCF contained TTX (1 $\mu \mathrm{M})$. B , Cumulative plots of the interevent interval distribution of $\mathrm{mEPSC}$ before and after perfusion of capsaicin in this recording ( $p<0.05$, Kolmogorov-Smirnov test). C, Effects of capsaicin (1 $\mu \mathrm{m})$ on mEPSC frequency at 8-10 min after agonist application alone and in the presence of capsazepine, expressed as a percentage of the control frequency in TTX. Error bars indicate SE.

tude before application of capsaicin was $15.1 \pm 0.4 \mathrm{pA}(n=5$; range, $14-16 \mathrm{pA}$ ) and after bath application of $1 \mu \mathrm{M}$ of capsaicin was $19.8 \pm 1.9 \mathrm{pA}$ (range, 13-26 pA). The effect of capsaicin on mEPSC frequency was prevented by preapplication of VR1 antagonist capsazepine $(20 \mu \mathrm{M} ; 9.4 \pm 2.7 \mathrm{~Hz}$ in capsazepine vs $14.2 \pm 4.5 \mathrm{~Hz}$ in capsaicin; $n=5 ; p>0.05$ ). In 12 additional neurons recorded in current-clamp at rest, the membrane potential changed by $<1 \mathrm{mV}$ after capsaicin application (data not shown). These data are consistent with the hypothesis that VR1 increases glutamate release in the DMV.

\section{Discussion}

Vanilloid receptors are coupled to ligand-gated ion channels that flux cations, including $\mathrm{Ca}^{2+}$ (Montell, 2001). VR1 activation typically increases excitability of neurons and synaptic terminals, and consequently enhances synaptic glutamate release. Activity at VR1 receptors is typically studied at the cellular level in the context of somatic or visceral sensory modulation (Tominaga et al., 1998; Yang et al., 1998; Zygmunt et al., 1999; Hwang et al., 2000; Bailey et al., 2002; Doyle et al., 2002; Evans et al., 2003; Jin et al., 2004a). Activation of VR1 can be achieved by increasing the temperature above $42^{\circ} \mathrm{C}$ or by lowering the $\mathrm{pH}$ below physiological levels (Tominaga et al., 1998; Premkumar and Ahern, 2000), conditions which cannot be met without disturbing normal brain activity. Centrally, several ethanolamide-based endocannabinoids such as AEA bind VR1 as well as CB1R, both of which are located throughout the DVC (Van Sickle et al., 2001; Patterson et al., 2003; Derbenev et al., 2004a). In the DMV, tonically applied AEA and other cannabinoids activate CB1R and suppress synaptic inputs over a period of several minutes (Derbenev et al., 2004a), although AEA often causes a transient increase in synap- tic frequency. In dorsal horn (Jennings et al., 2003) and substantia nigra (Marinelli et al., 2003), AEA enhances glutamatergic EPSCs, but not GABAergic IPSCs, effects that are suppressed by VR1 antagonists and mimicked by capsaicin. Here, AEA rapidly activated VR1, and capsaicin was used to selectively bind VR1 receptors (i.e., versus $\mathrm{CB} 1 \mathrm{R}$ ). The most prominent initial response to capsaicin or endocannabinoids was a potent VR1mediated increase in synaptic GABA release.

In the presence of TTX, capsaicin rapidly increased the frequency of mIPSCs in DMV neurons, supporting a role for VR1 in inhibiting the vagal motor output. There was no capsaicininduced change in mIPSC amplitude, resting membrane potential, or holding current in the DMV neurons, suggesting a lack of direct postsynaptic VR1 activity. However, these results are consistent with the hypothesis that VR1 activation enhances asynchronous GABA release by acting at presynaptic terminals. Glutamate application increased mIPSC frequency, suggesting that presynaptic glutamate receptors regulate GABA release in the $\mathrm{DMV}$, and glutamate neurotransmission was necessary for the facilitation of mIPSC frequency by VR1 activation. Presynaptic metabotropic glutamate receptors modulate GABA release in the NTS (Jin et al., 2004b) and presynaptic ionotropic glutamate receptors modulate neurotransmitter release in other brain regions (Liu et al., 1999; Cossart et al., 2001), although these have not been examined previously in the DMV. Ionotropic or metabotropic glutamate receptor antagonists suppressed the capsaicin-induced increase in MIPSC frequency in DMV neurons, implicating both receptor subtypes in the response. This may best be explained by activation of VR1 located on glutamatergic terminals that contact GABAergic terminals, which, in turn, synapse on DMV neurons (supplemental Fig. 1, available at www.jneurosci.org as supplemental material). In this heterosynaptic arrangement, activation of VR1 increases $\mathrm{Ca}^{2+}$ influx in glutamatergic terminals, increasing glutamate release ( $\mathrm{Li}$ et al., 2004). The glutamate subsequently binds postsynaptically to receptors on DMV neurons, as indicated by an increase in mEPSC frequency. It also binds presynaptically to multiple receptor types on GABAergic terminals that synapse with DMV neurons, increasing terminal excitability. The increased GABA release then inhibits the DMV neurons and decreases their overall excitability. These VR1-containing glutamatergic inputs may originate from several sources, especially neurons of the NTS (Travagli et al., 1991; Davis et al., 2004) or primary vagal afferents (Rinaman et al., 1989). It is also conceivable that VR1-induced glutamate release triggers release of an undefined retrograde messenger from the postsynaptic cell (e.g., occult glutamate, acetylcholine, ATP, etc.), which in turn feeds back and enhances GABA release. Although no direct evidence of activity at postsynaptic receptors was observed after VR1 activation, effects on nearby neural or glial cells cannot be ruled out.

Stimulation of the NTS evoked IPSCs in the DMV, which exhibited paired-pulse depression. The evoked IPSCs and the paired-pulse ratio were not altered by capsaicin with the same time course as the increase in MIPSC frequency, consistent with the notion that the VR1 are not primarily located directly on GABA terminals. Interestingly, the eventual decrease in evoked IPSC amplitude occurred concurrently with a VR1-mediated enhancement of mIPSC frequency. Analogous to VR1-mediated effects on EPSCs in substantia nigra or dorsal horn (Yang et al., 1998; Marinelli et al., 2003), the reduction in evoked IPSC amplitude may involve mechanisms resultant from sustained calcium influx or depolarization of afferent neurons or terminals. An inactivating, VR1-mediated inward current is observed in a 
subset of NTS neurons (Doyle et al., 2002) and could contribute to the eventual diminution of responses evoked after stimulating the NTS. Thus, VR1 activation could facilitate spontaneous glutamate or GABA release by acting at presynaptic receptors, while reducing action potential-evoked responses via a depolarization block (Katz and Miledi, 1969) or partial depletion of the calciumdependent, readily releasable vesicle pool in the terminal (Yang et al., 1999; Li et al., 2004). The heterogeneous nature of the axons activated by electrical stimulation of the NTS may also contribute to the change in evoked response over time, which could include VR1-mediated release of a different modulator substance (e.g., a neuropeptide) that secondarily enhances GABA release. Alternatively, a delay in the effect on evoked IPSCs could result from an activity-dependent translocation of VR1 into GABA terminals from the cytosol, as occurs for $\mu$-opioid receptors (Browning et al., 2004). Endogenously released agonists (e.g., AEA) would likely be cleared relatively rapidly by reuptake or degradation mechanisms, which would be expected to minimize the synaptic depletion, depolarization block, or slow activation of other modulatory systems in vivo.

Capsaicin also increased the frequency of mEPSCs to a similar extent as mIPSCs. Thus, it is possible that the physiological effects of VR1 agonists in the DMV also depend on the activity state of the nucleus or the predominance of the type of input received by a given set of neurons. Several studies showed that activation of VR1 alters a variety of physiological responses, including increasing gastric acid secretion (Minowa et al., 2001) and decreasing respiratory rate, in rats (Geraghty and Mazzone, 2002), and inducing retching in dogs (Shiroshita et al., 1997). All neurons tested responded to capsaicin with an increase in mIPSC frequency, and the effect of VR1 activation did not appear to differ between neurons in different parts of the DMV. It seems unlikely that the effect is limited to control of a particular organ system. The dual excitatory (i.e., cholinergic) and inhibitory (i.e., noncholinergic, nonadrenergic) pathways of the vagus peripherally allow for excitation and/or inhibition of DMV neurons to lead to inhibition of smooth muscle (D'Amato et al., 1992; Grundy et al., 1993; Desai et al., 1994; Paterson et al., 2000). Unfortunately, no evidence exists to directly correlate morphological or electrophysiological properties of individual DMV neurons with their final effect on the viscera, so it is currently impossible to determine in a slice preparation which functional vagal pathway is affected by a given DMV neuron. Regardless of the final pathway, during periods of normal neural activity in the DMV, VR1 effects on GABAergic inputs would be prominent. But during rare quiescent periods, enhanced glutamatergic inputs might make neurons more excitable. It has been similarly suggested that the actions of opioids or hypocretins in the DVC may depend on activity state in specific local circuits (Davis et al., 2003; Browning et al., 2004). Understanding mechanisms leading to release of endogenous agonist will be useful for understanding the relationship between VR1 activation and neural activity in the DMV.

The immediate, rapid effect in the DMV of the endocannabinoid, AEA is a VR1-mediated enhancement of synaptic (particularly GABAergic) input, whereas the CB1R-mediated effects include a suppression of that same synaptic input over time (Derbenev et al., 2004a). Notably, we reported previously a suppression of mIPSC frequency by AEA in experiments done in the presence of glutamate receptor antagonists (Derbenev et al., 2004a). Thus, endocannabinoids activate both VR1 and CB1R to alter GABA release in the DMV. As is the case for several other neuroactive substances (e.g., glutamate, serotonin, acetylcholine, etc.), a single ligand (i.e., endocannabinoid) activates a rapid, ionotropic receptor-mediated response (i.e., VR1) that is replaced by a longer-lasting metabotropic receptor-mediated response (i.e., CB1R). For endocannabinoids in the DMV, understanding the final physiological outcome will require identification of events causing endocannabinoid release in this system. Regardless of the trigger, brief endocannabinoid release will likely affect DMV motor output to the viscera differently than prolonged stimuli. For gastric control, which many of these neurons probably accomplish, this means that a stimulus, such as strong depolarization (Wilson and Nicoll, 2001) or glucocorticoid activity (Di et al., 2003, 2005), might diminish and then increase gastric contractility if the stimulus remains in place. Endocannabinoids released endogenously at specific synaptic sites would likely have selective effects on synaptic input, which could include a rapid enhancement of inhibitory input, but may eventually suppress all input under conditions of prolonged activation. Separating the effects of exogenously applied agonists from activity caused by endogenous release will be required to understand endocannabinoid activity in this and other neural systems that express both CB1R and VR1.

\section{References}

Acs G, Blumberg PM (1994) [ $\left.{ }^{3} \mathrm{H}\right]$ Resiniferatoxin binding to pig dorsal horn membranes display a positive cooperativity. Life Sci 55:337-346.

Acs G, Palkovits M, Blumberg PM (1996) Specific binding of $\left[{ }^{3} \mathrm{H}\right]$ Resiniferatoxin by human and rat preoptic area, locus ceruleus, medial hypothalamus, reticular formation and ventral thalamus membrane preparations. Life Sci 59:1899-1908.

Bailey TW, Jin YH, Doyle MW, Andresen MC (2002) Vanilloid-sensitive afferents activate neurons with prominent A-type potassium currents in nucleus tractus solitarius. J Neurosci 22:8230-8237.

Browning KN, Kalyuzhny AE, Travagli RA (2004) $\mu$-Opioid receptor trafficking on inhibitory synapses in the rat brainstem. J Neurosci 24:7344-7352.

Caterina MJ, Schumacher MA, Tominaga M, Rosen TA, Levine JD, Julius D (1997) The capsaicin receptor: a heat-activated ion channel in the pain pathway. Nature 389:816-824.

Cossart R, Tyzio R, Dinocourt C, Esclapez M, Hirsch JC, Ben-Ari Y, Bernard C (2001) Presynaptic kainate receptors that enhance the release of GABA on CA1 hippocampal interneurons. Neuron 29:497-508.

D'Amato M, Curro D, Montuschi P (1992) Evidence for dual components in the non-adrenergic non-cholinergic relaxation in the rat gastric fundus: role of endogenous nitric oxide and vasoactive intestinal polypeptide. J Auton Nerv Syst 37:175-186.

Davis SF, Williams KW, Xu W, Glatzer NR, Smith BN (2003) Selective enhancement of synaptic inhibition by hypocretin (orexin) in rat vagal motor neurons: implications for autonomic regulation. J Neurosci 23:3844-3854.

Davis SF, Derbenev AV, Williams KW, Glatzer NR, Smith BN (2004) Excitatory and inhibitory local circuit input to the rat dorsal motor nucleus of the vagus originating from the nucleus tractus solitarius. Brain Res 1017:208-217.

Derbenev AV, Stuart TC, Smith BN (2004a) Cannabinoids suppress synaptic input to neurons of the rat dorsal motor nucleus of the vagus nerve. J Physiol (Lond) 559:923-938.

Derbenev AV, Monroe MJ, Smith BN (2004b) Activation of VR1 receptors on GABAergic and glutamatergic synaptic terminals contacting neurons in the rat dorsal motor nucleus of the vagus by endocannabinoids. Soc Neurosci Abstr 30:891.3.

Desai KM, Warner TD, Bishop AE, Polak JM, Vane JR (1994) Nitric oxide, and not vasoactive intestinal peptide, as the main neurotransmitter of vagally induced relaxation of the guinea pig stomach. Br J Pharmacol 113:1197-1202.

Di S, Malcher-Lopes R, Halmos KC, Tasker JG (2003) Nongenomic glucocorticoid inhibition via endocannabinoid release in the hypothalamus: a fast feedback mechanism. J Neurosci 23:4850-4857.

Di S, Malcher-Lopes R, Marcheselli VL, Bazan NG, Tasker JG (2005) Rapid glucocorticoid-mediated endocannabinoid release and opposing regulation of glutamate and gamma-aminobutyric acid inputs to hypothalamic magnocellular neurons. Endocrinology 146:4292-4301. 
Doyle MW, Bailey TW, Jin YH, Andresen MC (2002) Vanilloid receptors presynaptically modulate cranial visceral afferent synaptic transmission in nucleus tractus solitarius. J Neurosci 22:8222-8229.

Drew GM, Vaughan CW (2004) Multiple metabotropic glutamate receptor subtypes modulate GABAergic neurotransmission in rat periaqueductal grey neurons in vitro. Neuropharmacology 46:927-934.

Evans C, Baxi S, Neff R, Venkatesan P, Mendelowitz D (2003) Synaptic activation of cardiac vagal neurons by capsaicin sensitive and insensitive sensory neurons. Brain Res 979:210-215.

Geraghty DP, Mazzone SB (2002) Respiratory actions of vanilloid receptor agonists in the nucleus of the solitary tract: comparison of resiniferatoxin with non-pungent agents and AEA. Br J Pharmacol 137:919-927.

Grundy D, Gharib-Naseri MK, Hutson D (1993) Role of nitric oxide and vasoactive intestinal polypeptide in vagally mediated relaxation of the gastric corpus in the anaesthetized ferret. J Auton Nerv Syst 43:241-246.

Hwang SW, Cho H, Kwak J, Lee SY, Kang CJ, Jung J, Cho S, Min KH, Suh YG, Kim D, Oh U (2000) Direct activation of capsaicin receptors by products of lipoxygenases: endogenous capsaicin-like substances. Proc Natl Acad Sci USA 97:6155-6160.

Jennings EA, Vaughan CW, Roberts LA, Christie MJ (2003) The actions of AEA on rat superficial medullary dorsal horn neurons in vitro. J Physiol (Lond) 548:121-129.

Jin YH, Bailey TW, Li B, Schild JH, Andresen MC (2004a) Purinergic and vanilloid receptor activation releases glutamate from separate cranial afferent terminals in nucleus tractus solitarius. J Neurosci 24:4709-4717.

Jin YH, Bailey TW, Andresen MC (2004b) Cranial afferent glutamate heterosynaptically modulates GABA release onto second-order neurons via distinctly segregated metabotropic glutamate receptors. J Neurosci 24:9332-9340.

Katz B, Miledi R (1969) Spontaneous and evoked activity of motor nerve endings in calcium Ringer. J Physiol (Lond) 203:689-706.

Laughton WB, Powley TL (1987) Localization of efferent function in the dorsal motor nucleus of the vagus. Am J Physiol 252:13-25.

Li DP, Chen SR, Pan HL (2004) VR1 receptor activation induces glutamate release and postsynaptic firing in the paraventricular nucleus. J Neurophysiol 92:1807-1816.

Liu QS, Patrylo PR, Gao XB, van den Pol AN (1999) Kainate acts at presynaptic receptors to increase GABA release from hypothalamic neurons. J Neurophysiol 82:1059-1062.

Marinelli S, Di Marzo V, Berretta N, Matias I, Maccarrone M, Bernardi G, Mercuri NB (2003) Presynaptic facilitation of glutamatergic synapses to dopaminergic neurons or the rat substantia nigra by endogenous stimulation of vanilloid receptors. J Neurosci 23:3136-3144.

Mezey E, Toth ZE, Cortright DN, Arzubi MK, Krause JE, Elde R, Guo A, Blumberg PM, Szallasi A (2000) Distribution of mRNA for vanilloid receptor type 1 (VR1), and VR1-like immunoreactivity, in the central nervous system of the rat and human. Proc Natl Acad Sci USA 97:3655-3660.

Minowa S, Shizuko T, Syunji H, Watanabe K, Murayama T (2001) Stimulatory effect of centrally injected capsaicin, an agonist of vanilloid receptors, on gastric acid secretion in rats. Eur J Pharmacol 428:349-356.

Montell C (2001) Physiology, phylogeny, and functions of the TRP superfamily of cation channels. Sci STKE 90:RE1.

Paterson CA, Anvari M, Tougas G, Huizinga JD (2000) Nitrergic and cho- linergic vagal pathways involved in the regulation of canine proximal gastric tone: an in vivo study. Neurogastroenterol Motil 12:301-306.

Patterson LM, Zheng H, Ward SM, Berthoud HR (2003) Vanilloid receptor (VR1) expression in vagal afferent neurons innervating the gastrointestinal tract. Cell Tissue Res 311:277-287.

Premkumar LS, Ahern GP (2000) Induction of vanilloid receptor channel activity by protein kinase C. Nature 28:985-990.

Raybould HE, Holzer P, Thiefin G, Holzer HH, Yoneda M, Tache YF (1991) Vagal afferent innervation and regulation of gastric function. Adv Exp Med Biol 298:109-127.

Regehr W, Stevens C (2001) Physiology of synaptic transmission and shortterm plasticity. In: Synapses (Cowan WM, Sudhoff TC, Stevens CF, eds), pp 135-175. Baltimore: Johns Hopkins UP.

Rinaman L, Card JP, Schwaber JS, Miselis RR (1989) Ultrastructural demonstration of a gastric monosynaptic vagal circuit in the nucleus of the solitary tract in rat. J Neurosci 9:1985-1996.

Rogers RC, McTigue DM, Hermann GE (1996) Vagal control of digestion: modulation by central neural and peripheral endocrine factors. Neurosci Biobehav Rev 20:57-66.

Shiroshita Y, Tomoshige K, Fukuda H (1997) Capsaicin in the 4th ventricle abolishes retching and transmission of emetic vagal afferents to solitary nucleus neurons. Eur J Pharmacol 339:183-192.

Szallasi A, Blumberg PM (1999) Vanilloid (capsaicin) receptors and mechanisms. Pharmacol Rev 51:159-211.

Szallasi A, Di Marzo V (2000) New perspectives in enigmatic vanilloid receptors. Trends Neurosci 23:491-497.

Szallasi A, Nilsson S, Farkas-Szallasi T, Blumberg PM, Hokfelt T, Lundberg JM (1995) Vanilloid (capsaicin) receptors in the rat: distribution in the brain, regional differences in the spinal cord, axonal transport to the periphery, and depletion by systemic vanilloid treatment. Brain Res 703:175-183.

Szolcsányi J (2000) AEA and the question of its functional role for activation of capsaicin receptors. Trends Pharmacol Sci 21:203-204.

Tominaga M, Caterina MJ, Malmberg AB, Rosen TA, Gilbert H, Skinner K, Raumann BE, Basbaum AI, Julius D (1998) The cloned capsaicin receptor integrates multiple pain-producing stimuli. Neuron 21:531-543.

Travagli RA, Gillis RA, Rossiter CD, Vicini S (1991) Glutamate and GABAmediated synaptic currents in neurons of the rat dorsal motor nucleus of the vagus. Am J Physiol 260:G531-G536.

Van Sickle MD, Oland LD, Ho W, Hillard CJ, Mackie K, Davison JS, Sharkey KA (2001) Cannabinoids inhibit emesis through CB1 receptors in the brainstem of the ferret. Gastroenterology 121:767-774.

Wilson RI, Nicoll RA (2001) Endogenous cannabinoids mediate retrograde signalling at hippocampal synapses. Nature 410:588-592.

Yang K, Kumamoto E, Furue H, Yoshimura M (1998) Capsaicin facilitates excitatory but not inhibitory synaptic transmission in substantia gelatinosa of the rat spinal cord. Neurosci Lett 255:135-138.

Yang K, Kumamoto E, Furue H, Li Y, Yoshimura M (1999) Action of capsaicin on dorsal root-evoked synaptic transmission to substantia gelatinosa neurons in adult rat spinal cord slices. Brain Res 830:268-273.

Zygmunt PM, Petersson J, Andersson DA, Chuang H, Sorgard M, Di Marzo V, Julius D, Hogestatt ED (1999) Vanilloid receptors on sensory nerves mediate the vasodilator action of AEA. Nature 400:452-457. 